\title{
Journal of

\section{A series of CBP-derivatives as host materials for blue phosphorescent organic light-emitting diodes}

\author{
Pamela Schrögel, ${ }^{a}$ Aušra Tomkevičienè, $\dagger^{a}$ Peter Strohriegl, ${ }^{* a}$ Sebastian T. Hoffmann, ${ }^{b}$ Anna Köhler ${ }^{b}$ \\ and Christian Lennartz ${ }^{c}$
}

\author{
Received 2nd October 2010, Accepted 15th November 2010 \\ DOI: 10.1039/c0jm03321a
}

\begin{abstract}
We report a series of CBP-derivatives with superior thermal and electronic properties for the use as host materials for blue electrophosphorescent organic light emitting diodes. We applied a systematic variation of the substitution pattern in the 2- and 2'-position of the biphenyl unit and the 3- and 6-position of the carbazole moieties. In contrast to the crystalline parent compound $\mathbf{C B P}$, all methyl and trifluoromethyl substituted derivatives show amorphous behaviour. Substitution in the 2- and 2 -position of the biphenyl causes a twisting of the phenyl rings. Hence, the degree of conjugation of the molecules is limited which leads to enlarged triplet energies of approximately $2.95 \mathrm{eV}$ compared to $2.58 \mathrm{eV}$ for CBP. The methyl substitution at the active 3- and 6-position of the pendant carbazole units yields materials with an electrochemically stable behaviour against oxidation.
\end{abstract}

\section{Introduction}

Recent developments of efficient emitters for organic light emitting diodes (OLEDs) are often focused on phosphorescent transition metal complexes. Due to elementary spin statistics $75 \%$ triplet excitons and $25 \%$ singlet excitons are formed on initial charge recombination. By fast intersystem crossing all singlet excitons will be efficiently converted to the triplet state. Hence, with these phosphorescent emitters the theoretical limit of the internal quantum efficiency is $100 \%{ }^{1-3}$ Due to concentration quenching effects phosphorescent materials show a loss in efficiency if the neat material is used in OLEDs. To avoid selfquenching it is necessary to dope the emitters into an appropriate host. It is essential that the triplet energy $\Delta E\left(T_{1}-S_{0}\right)$ of the host is higher than that of the emitter in order to prevent energy back transfer from the phosphorescent guest to the host. 4,4'-Bis(9-carbazolyl)-biphenyl (CBP) is a widely used matrix material for phosphorescent emitters. Due to its triplet energy $\Delta E$ $\left(T_{1}-S_{0}\right)$ of $2.55 \mathrm{eV},{ }^{4} \mathbf{C B P}$ is a suitable matrix for green phosphorescent emitters like tris(2-phenylpyridine)iridium(III) $\left(\operatorname{Ir}(\text { ppy })_{3}\right){ }^{3,5}$ Blue emitting materials such as the commonly used bis((4,6-difluorophenyl)-pyridinato- $N, C 2)$ picolinate-iridium(III) (FIrpic) $\left(\Delta E\left(T_{1}-S_{0}\right)=2.62 \mathrm{eV}^{6}\right)$ require hosts with higher

${ }^{a}$ Lehrstuhl Makromolekulare Chemie I, Universität Bayreuth, 95440 Bayreuth, Germany. E-mail: peter.strohriegl@uni-bayreuth.de; Fax. +49-921-553206; Tel: +49-921-553296

${ }^{b}$ Lehrstuhl Experimentalphysik II, Universität Bayreuth, 95440 Bayreuth, Germany

${ }^{c} B A S F$ SE, 67056 Ludwigshafen, Germany

$\dagger$ Current address: Kaunas University of Technology, Department of Organic Technology, Radvilenu pl. 19, LT-50254 Kaunas, Lithuania triplet energies. The key to such materials is to confine the conjugated system in the host molecules. In $N, N^{\prime}$-dicarbazolyl3,5-benzene ( $\mathrm{mCP}$ ) this is accomplished by exchanging the biphenyl group by a single benzene unit in combination with meta conjugation instead of para which leads to a triplet energy of approximately $2.90 \mathrm{eV} .^{7,8}$ Another approach to enlarge the triplet energy of CBP based materials comprises the attachment of two methyl groups in the 2- and $2^{\prime}$-position of the central biphenyl which leads to $4,4^{\prime}$-bis(9-carbazolyl)-2,2'-dimethylbiphenyl (CDBP) with a triplet energy of $2.79 \mathrm{eV} .4,9,10$ Over the years many different carbazole based host materials have been described. ${ }^{11-13}$ Ma et al. recently described a series of nonconjugated carbazole host materials where the linkage groups between two carbazole moieties were varied. This leads to a loss of conjugation in the molecules and high triplet energies. ${ }^{14}$

Another crucial requirement for the successful operation of OLEDs is the ability of the materials to form stable amorphous films. ${ }^{15}$ This property guarantees that the emitter is uniformly diluted in the host to minimize the effect of concentration quenching. In addition, the absence of grain boundaries, which may act as trap states, makes the use of organic glasses as OLED materials advantageous. ${ }^{16,17}$ The glass transition temperature of materials for OLED applications is ideally above $100{ }^{\circ} \mathrm{C}$. In general, the introduction of bulky substituents hinders packing of the molecules and leads to an amorphous behaviour of the material. On the other hand, detrimental effects on the charge carrier transport properties are observed. 9-(4-tert-Butylphenyl)3,6-bis(triphenylsilyl)-carbazole (CzSi), for example, combines appropriate thermal properties with a confined conjugated system; however, the hole mobility of $5 \times 10^{-5} \mathrm{~cm}^{2} \mathrm{~V}^{-1} \mathrm{~s}^{-1}$ is rather low. ${ }^{18}$ By exchanging the triphenylsilyl groups by trityl 
groups the hole mobility rises by one order of magnitude to $5 \times$ $10^{-4} \mathrm{~cm}^{2} \mathrm{~V}^{-1} \mathrm{~s}^{-1}$. However, this material shows a stronger efficiency roll off at higher current densities than $\mathrm{CzSi} .{ }^{19}$

We have prepared a series of CBP derivatives in which the substitution pattern in both the 2- and $2^{\prime}$-position of the biphenyl unit and in the 3- and 6-position of the carbazole unit has been systematically varied (Scheme 1). The attachment of the methyl and trifluoromethyl groups in these positions leads to amorphous materials with large triplet energies making them suitable as hosts for blue phosphorescent emitters.

In this work we report the synthesis of five amorphous derivatives of CBP together with their thermal and optical properties. The energy levels have been measured by cyclic voltammetry and absorption measurements. Furthermore, a detailed cyclic voltammetry study of the materials gives insight into the

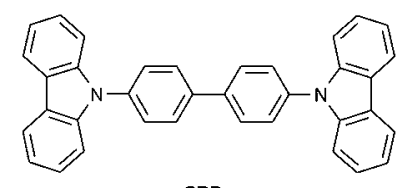

CBP

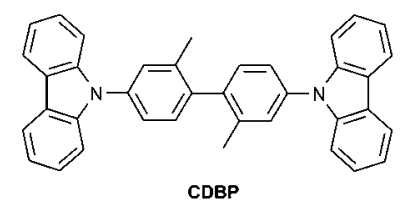<smiles>[R]c1ccc2c(c1)c1cc([R])ccc1n2-c1ccc(-c2ccc(-n3c4ccc([R])cc4c4cc([R])ccc43)cc2[R3])c([R3])c1</smiles>

$\mathbf{R}_{1}: \mathrm{H}$ or $\mathrm{CH}_{3}$

$\mathbf{R}_{3}: \mathrm{CH}_{3}$ or $\mathrm{CF}_{3}$

Scheme 1 Chemical structures of the substituted 4,4'-bis(9-carbazolyl)biphenyls.

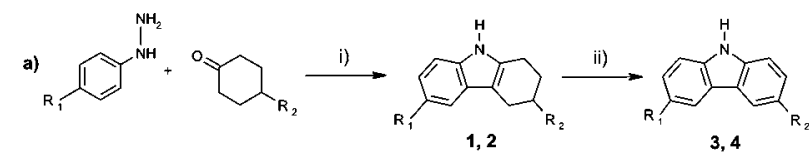

b)
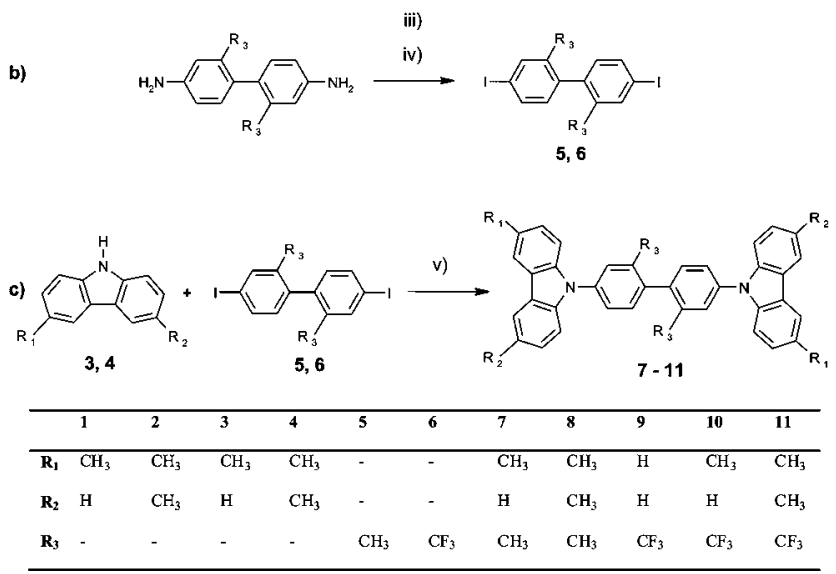

Scheme 2 Synthetic routes to (a) methyl substituted carbazoles, (b) tilted biphenyls and (c) methyl substituted CBP derivatives. Reagents and conditions: (i) acetic acid, $80{ }^{\circ} \mathrm{C}, 30 \mathrm{~min}$; (ii) $\mathrm{Pd}(\mathrm{C})$, 1,2,4-trimethylbenzene, $170{ }^{\circ} \mathrm{C}, 6 \mathrm{~h}$; (iii) $\mathrm{H}_{2} \mathrm{O}, \mathrm{HCl}, \mathrm{NaNO}_{2}, 0-5{ }^{\circ} \mathrm{C}$; (iv) $\mathrm{I}_{2}, \mathrm{NaI}$, dichloromethane, rt, $24 \mathrm{~h}$; (v) $\mathrm{Cu}, \mathrm{K}_{2} \mathrm{CO}_{3}, 18$-crown-6, o-dichlorobenzene, reflux, $24 \mathrm{~h}$. electrochemical stability of the $\mathbf{C B P}$ derivatives. In addition, DFT calculations were carried out to obtain the ground state geometries of the CBP derivatives.

\section{Results and discussion}

\section{Synthesis}

In a two step synthesis 3-methylcarbazole 3 and 3,6-dimethylcarbazole 4 were prepared from 4-methyl-phenylhydrazine and cyclohexanone or 4-methyl-cyclohexanone as the starting materials in a Borsche reaction (Scheme 2a). The first step yields the 1,2,3,4-tetrahydrocarbazoles $\mathbf{1}$ and $\mathbf{2}$ which are subsequently dehydrogenated with palladium on activated charcoal. ${ }^{20,21}$

The synthesis of the diiodobiphenyls is shown in Scheme 2b. 4,4'-Diiodo-2,2'-dimethylbiphenyl 5 and 4,4'-diiodo-2,2'-bis(trifluoromethyl)biphenyl $\mathbf{6}$ were prepared by diazotization of the corresponding diamine and subsequent reaction with sodium iodide. $^{22}$ The carbazole containing host materials 7-11 were prepared via the Ullmann coupling reaction of diiodo compound 5 or $\mathbf{6}$ with carbazole or the methylcarbazoles $\mathbf{3}$ and 4, respectively (Scheme 2c).

Mass spectrometry, ${ }^{1} \mathrm{H}-\mathrm{NMR}$ spectroscopy and ${ }^{13} \mathrm{C}-\mathrm{NMR}$ spectroscopy were used to identify the materials and the data are given in the Experimental section. The purity of the materials was monitored by SEC measurements.

\section{Thermal properties}

The thermal properties of the newly synthesized compounds were examined by thermogravimetric analysis (TGA) and differential scanning calorimetry (DSC) in a nitrogen atmosphere at a scanning rate of $10 \mathrm{~K} \mathrm{~min}{ }^{-1}$. All materials reveal high thermal stabilities, with an onset of weight loss at temperatures $\left(T_{\mathrm{ID}}\right)$ exceeding $310{ }^{\circ} \mathrm{C}$, as determined by TGA measurements (Table 1).

In Fig. 1, the DSC thermograms of CBP, the methyl substituted compound $\mathbf{8}$ and the trifluoromethyl derivative $\mathbf{1 1}$ are presented. The parent compound CBP shows a crystalline behaviour in the DSC. The melting peak is observed at $285^{\circ} \mathrm{C}$ and upon cooling the material crystallises at $183{ }^{\circ} \mathrm{C}$. In contrast,

Table 1 Thermal properties of the carbazole-substituted biphenyls CBP, CDBP, and $\mathbf{7 - 1 1 ^ { d }}$

\begin{tabular}{lllll}
\hline Entry & $T_{\mathrm{g}}{ }^{\circ} \mathrm{C}$ & $T_{\mathrm{m}} /{ }^{\circ} \mathrm{C}$ & $T_{\mathrm{cr}}{ }^{\circ} \mathrm{C}$ & $T_{\mathrm{ID}}{ }^{a} /{ }^{\circ} \mathrm{C}$ \\
\hline $\mathbf{C B P}$ & - & 283 & 205 & 365 \\
$\mathbf{C D B P}$ & 94 & - & - & 310 \\
$\mathbf{7}$ & 106 & - & - & 310 \\
$\mathbf{8}$ & 121 & 277 & $200^{c}$ & 312 \\
$\mathbf{9}$ & 100 & 232 & - & 310 \\
$\mathbf{1 0}$ & 105 & $210^{b}$ & - & 337 \\
$\mathbf{1 1}$ & 119 & $233^{b}$ & - & 333
\end{tabular}

${ }^{a} T_{\mathrm{ID}}$ is the temperature at which an initial loss of mass was observed in a thermogravimetric experiment with a heating rate of $10 \mathrm{~K} \mathrm{~min}^{-1}$ in a nitrogen atmosphere. ${ }^{b}$ Observed only in the first heating scan. ${ }^{c}$ Observed during the heating scan. ${ }^{d} T_{\mathrm{g}}$ : glass-transition temperatures, $T_{\mathrm{m}}$ : melting temperatures, $T_{\mathrm{cr}}$ : crystallisation temperatures and $T_{\mathrm{ID}}$ : initial decomposition temperatures. 


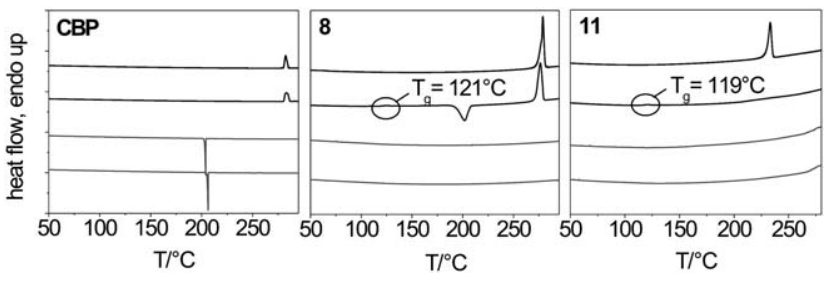

Fig. 1 DSC traces of carbazole based compounds CBP, 8, and $\mathbf{1 1}$ at a scan rate of $10 \mathrm{~K} \mathrm{~min}-1, \mathrm{~N}_{2}$ atmosphere. Shown are from top to bottom: the first heating, second heating, first cooling and second cooling traces.

compound 8 exhibits a melting peak at $277^{\circ} \mathrm{C}$. In the cooling cycle no crystallisation is observed as the material solidifies in an amorphous phase. In the second heating curve the glass transition is observed at $121{ }^{\circ} \mathrm{C}$ followed by a recrystallisation at $200{ }^{\circ} \mathrm{C}$. The $\mathrm{CF}_{3}$-substituted derivative $\mathbf{1 1}$ remains in the amorphous phase after the first melting at $233{ }^{\circ} \mathrm{C}$. In the second heating only the glass transition at $119^{\circ} \mathrm{C}$ is observed.

These results show that by the introduction of additional methyl- and trifluoromethyl groups into the basic CBP structure the thermal properties are improved. While the parent compound CBP is highly crystalline, all CBP derivatives 7-11 reveal high glass transition temperatures ranging from 94 to 121 ${ }^{\circ} \mathrm{C}$ and all materials remain amorphous upon cooling (Table 1). For OLED applications materials with high glass transition temperatures $\left(T_{\mathrm{g}} \approx 100{ }^{\circ} \mathrm{C}\right)$ are advantageous for the operational stability of the device. In a morphologically stable amorphous host material the emitter molecules are homogenously diluted which prevents concentration quenching. The melting, crystallisation and glass transition temperatures of all derivatives are summarised in Table 1.

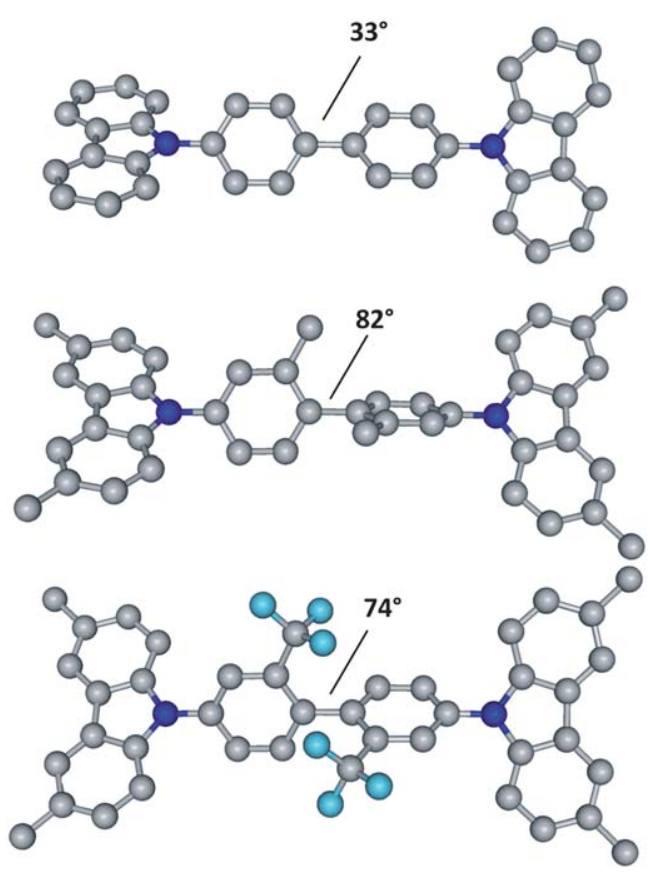

Fig. 2 Geometry optimized structures of CBP, $\mathbf{8}$, and $\mathbf{1 1}$ (top to bottom) with different torsion angles.

\section{Optical properties}

The compounds CBP, CDBP and 7-11 were analyzed by UV/ Vis, fluorescence and phosphorescence spectroscopy. In addition, the molecular structures of all compounds were simulated via DFT-calculations to facilitate the interpretation of the experimental results. The geometry optimized structures of CBP, $\mathbf{8}$, and $\mathbf{1 1}$ are visualized in Fig. 2. Due to the steric demand of the substituents at the 2- and 2'-position at the biphenyl unit, $\mathbf{8}$ and 11 reveal twisted molecular structures with torsion angles between the two phenyl rings of the biphenyl unit of $82^{\circ}$ and $74^{\circ}$ which are significantly higher compared to the more planar CBP $\left(33^{\circ}\right)$.

Fig. 3 displays the room temperature absorption and fluorescence spectra taken from $10^{-5} \mathrm{M}$ cyclohexane solutions together with the phosphorescence spectra obtained from $10 \mathrm{wt} \%$ solid solutions of CBP, 8, and 11 in PMMA at $10 \mathrm{~K}$. In order to understand how the substitutions affect the excited states of these compounds, we first consider the effect of the methyl substitution at the central biphenyl unit by comparing CBP and $\mathbf{8}$. For $\mathbf{8}$, the first and second absorption are at $351 \mathrm{~nm}$ and $300 \mathrm{~nm}$ which can both be assigned to the absorption of the 3,6-dimethylcarbazole units. In the case of $\mathbf{C B P}$, the features associated with transitions localized on the carbazole are still present at $339 \mathrm{~nm}$ and $290 \mathrm{~nm}$. The observed bathochromic shift of approximately $10 \mathrm{~nm}$ in compound $\mathbf{8}$ is caused by the additional methyl groups at the

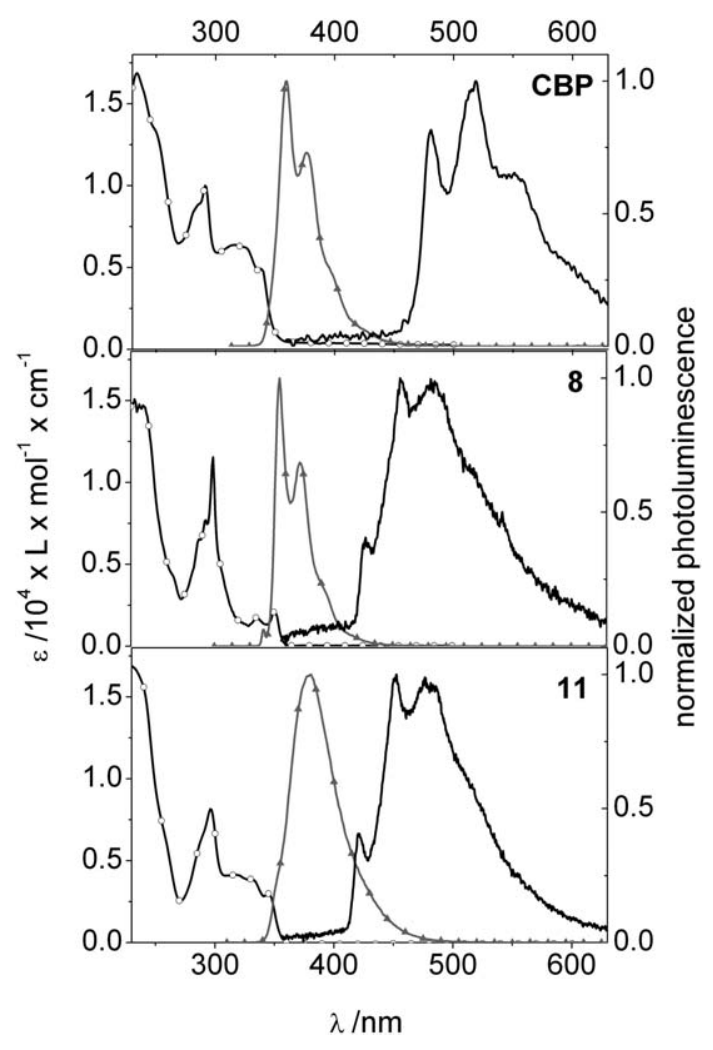

Fig. 3 Comparison of the absorption (dark grey with circles), fluorescence (light grey with triangles) and phosphorescence (black) spectra of CBP, 8, and 11. Absorption and fluorescence were taken in $10^{-5} \mathrm{M}$ cyclohexane solutions at $300 \mathrm{~K}$, phosphorescence was measured in $10 \mathrm{wt} \%$ solid solutions in PMMA at $10 \mathrm{~K}$. 
carbazole units. In CBP, however, there is an additional broad absorption centred at about $320 \mathrm{~nm}$. This feature is likely to be associated with transitions between orbitals that involve the central biphenyl unit of the molecule. In the fluorescence spectra, in contrast, CBP and $\mathbf{8}$ show very similar vibrational structures with a strong maximum at about $355 \mathrm{~nm}$ for both compounds. We now consider how changing the substituents on the central biphenyl unit from methyl to trifluoromethyl affects the optical transitions. While $\mathbf{8}$ shows the signature of the carbazole-based transitions in the absorption and fluorescence spectra, $\mathbf{1 1}$ has an additional contribution to the absorption, centred at about $325 \mathrm{~nm}$. As for CBP, we consider the additional absorption to involve the central biphenyl unit. The main difference of compound $\mathbf{1 1}$ compared to CBP and $\mathbf{8}$ is the observed featureless fluorescence centred at $410 \mathrm{~nm}$. The broad bathochromically shifted fluorescence is clearly not due to transitions localized on the carbazole. The absence of vibrational fine structure rather points to a charge-transfer type transition, for example from the carbazole moiety to the central, trifluoromethyl substituted biphenyl rings.

For applications of compounds 7-11 as host materials for blue phosphorescent emitters the triplet energies are of major interest. In the phosphorescence spectra of compounds 8 and 11, we observe two sharp peaks at $420 \mathrm{~nm}$ and $450 \mathrm{~nm}$ as well as a broad peak centred at $480 \mathrm{~nm}$. On the contrary, the emission of $\mathbf{C B P}$ is bathochromically shifted by $60 \mathrm{~nm}$. As a result, 8 and 11 reveal a triplet energy of approximately $2.95 \mathrm{eV}(420 \mathrm{~nm})$, significantly higher than that of CBP of $2.58 \mathrm{eV}$ (480 nm). Apparently, the conjugation between the two phenyl rings is interrupted by introducing $\mathrm{CH}_{3}$ and $\mathrm{CF}_{3}$ substituents at the 2- and 2'-position of the central biphenyl leading to higher triplet energies.

All results of the photophysical investigations of compounds CBP, CDBP, and 7-11 are summarised in Table 2. With increasing $\mathrm{CH}_{3}$-content on the pendant carbazole units in the series CDBP, 7, and $\mathbf{8}$ as well as in the series of $\mathbf{9 , 1 0}$, and $\mathbf{1 1}$ a small bathochromic shift is noticeable in both the absorption and fluorescence spectra. We attribute this to the electron donating effect of the $\mathrm{CH}_{3}$-units. All compounds which are twisted by substituents at the central biphenyl show triplet energies of approximately $2.95 \mathrm{eV}$. These high triplet energies of the materials CDBP and 7-11 make them suitable host materials for deep blue phosphorescent emitters. It should be noted that the triplet energies of $\mathbf{C B P}$ and $\mathbf{C D B P}$ are slightly higher than in neat films reported by Tokito et $a l^{\mathbf{4 , 9 , 1 0}}$ as in our case the phosphorescence spectroscopy was carried out in $10 \mathrm{wt} \%$ solid solutions of PMMA.

\section{Cyclic voltammetry}

The electrochemical behaviour of the CBP-derivatives was studied by cyclic voltammetry in a conventional three-electrode cell using a platinum working electrode, a platinum wire counter electrode, and a $\mathrm{Ag} / \mathrm{AgNO}_{3}$ reference electrode. In particular, the oxidation processes were investigated in dichloromethane solutions. The HOMO levels of the compounds were estimated from the half-wave potential of the first oxidation relative to ferrocene. The LUMO levels were calculated by adding the optical band gap to the HOMO levels. Table 3 lists the values for the HOMO and LUMO levels. In the CV-experiments CBP and CDBP show very similar HOMO levels of $5.63 \mathrm{eV}$ and $5.64 \mathrm{eV}$. This observation is not surprising as in both molecules the HOMO is mainly located on the electron rich carbazole units. In the case of the methyl substitution in the 3- and 6-position of the carbazole units the additional $+I$-effect on the carbazole shifts the HOMO levels to slightly higher values. The HOMO level is $5.56 \mathrm{eV}$ for compound 7 and $5.52 \mathrm{eV}$ for compound 8 . In the case of the compounds 9-11 the strong $-I$-effect of the trifluoromethyl substituents causes a decrease of the HOMO level of approximately $0.1 \mathrm{eV}$ (5.74 eV for 9) in comparison with CDBP $(5.64 \mathrm{eV})$. By the subsequent introduction of methyl groups at the carbazole moieties in compounds $\mathbf{1 0}$ and $\mathbf{1 1}$ the HOMO level rises again to $5.68 \mathrm{eV}$ and $5.65 \mathrm{eV}$, respectively. In contrast, the LUMO levels of all compounds are less affected by the introduction of the substituents on the carbazole units. However, in

Table 3 Experimentally determined energy levels of the CBP derivatives

\begin{tabular}{lll}
\hline Entry & $\mathrm{HOMO}^{a} / \mathrm{eV}$ & $\mathrm{LUMO}^{b} / \mathrm{eV}$ \\
\hline $\mathbf{C B P}$ & 5.63 & 2.16 \\
CDBP & 5.64 & 2.13 \\
$\mathbf{7}$ & 5.56 & 2.13 \\
$\mathbf{8}$ & 5.52 & 2.13 \\
$\mathbf{9}$ & 5.74 & 2.20 \\
$\mathbf{1 0}$ & 5.68 & 2.22 \\
$\mathbf{1 1}$ & 5.65 & 2.21
\end{tabular}

${ }^{a}$ Estimated from the half-wave potential of the first oxidation in the cyclic voltammetry measurements. ${ }^{b}$ Estimated from the HOMO values and the optical band gap.

Table 2 Optical properties of CBP, CDBP and the CBP-derivatives 7-11

\begin{tabular}{llllllr}
\hline Entry & $\lambda_{\mathrm{EA}}{ }^{a} / \mathrm{nm}$, solution & $\lambda_{\mathrm{EA}}{ }^{b} / \mathrm{nm}, \mathrm{film}$ & $\lambda^{\mathrm{RT}}{ }_{\mathrm{em}}{ }^{c} / \mathrm{nm}$ & $\lambda^{10 \mathrm{~K}}{ }_{\mathrm{em}}{ }^{d} / \mathrm{nm}$ & $\Delta E\left(S_{0}-S_{1}\right)^{e} / \mathrm{eV}$ & $\Delta E\left(T_{1}-S_{0}\right) / \mathrm{eV}$ \\
\hline CBP & 350 & 357 & 356,374 & 477 & 3.47 & 2.58 \\
$\mathbf{C D B P}$ & 346 & 353 & 342,358 & 419 & 3.51 & 2.95 \\
$\mathbf{7}$ & 353 & 361 & 349,366 & 417 & 3.43 & 2.97 \\
$\mathbf{8}$ & 357 & 365 & 355,372 & 421 & 3.54 & 2.95 \\
$\mathbf{9}$ & 343 & 350 & 368 & 419 & 3.46 & 2.95 \\
$\mathbf{1 0}$ & 350 & 358 & 373 & 419 & 3.44 & 2.95
\end{tabular}

${ }^{a}$ Edge of absorption measured in $10^{-5} \mathrm{M}$ cyclohexane solutions at room temperature. ${ }^{b}$ Edge of absorption measured on neat films at room temperature. ${ }^{c}$ Wavelengths of the intensity maxima of the fluorescence at $300 \mathrm{~nm}$ excitation of $10^{-5} \mathrm{M}$ cyclohexane solutions at room temperature. ${ }^{d}$ Wavelength of the highest energy maximum measured on film samples of $10 \mathrm{wt} \%$ compound in PMMA at $10 \mathrm{~K} .{ }^{e}$ The optical band gap was determined from the UV/ Vis absorption onset of neat films. 
compounds 9-11 the trifluoromethyl substitution at the biphenyl lowers the LUMO level slightly by approximately $8 \mathrm{meV}$ compared to compounds CDBP, 7, and $\mathbf{8}$.

These considerations show that the energy levels of the CBP derivatives can be fine tuned to some extent by the variation of the substitution pattern at the connecting biphenyl moiety as well as at the pendant carbazoles. Especially, the HOMO levels can be varied as can be seen in Fig. 4. Thus, with these slight variations in the molecular structure the energy levels of the different layers in an OLED can be adjusted to each other in order to minimize energy barriers within the device.

Cyclic voltammetry experiments with repeated cycles give an insight into the electrochemical stability of the CBP derivatives. As radical cations and anions are involved in charge transport processes the electrochemical stability of the materials used in electroluminescent devices contributes to the overall stability of the device. Fig. 5 shows the cyclic voltammograms with five repeated oxidation cycles of $\mathbf{C B P}, 7$, and 8 in $2 \times 10^{-3} \mathrm{M}$ dichloromethane solutions.

CBP reveals an irreversible oxidation behaviour as here oligomerisation reactions of the oxidised species can take place at the active 3- and 6-position of the carbazole units. This kind of dimerisation is known from triphenylamine and $N$-phenylcarbazole. The mechanism is shown in Fig. $6 .^{23,24}$ In the first step the molecule is oxidised at the electron lone pair of the nitrogen atom and a radical cation is formed. The radical stabilises into the 3-position of the carbazole where recombination of two radical molecules takes place under elimination of two protons.

The oligomeric species are oxidised more easily, i.e. at lower voltages. In the cyclic voltammogram the emerging signal at 0.6 $\mathrm{V}$ to $0.7 \mathrm{~V}$ is assigned to the oxidation of the newly formed

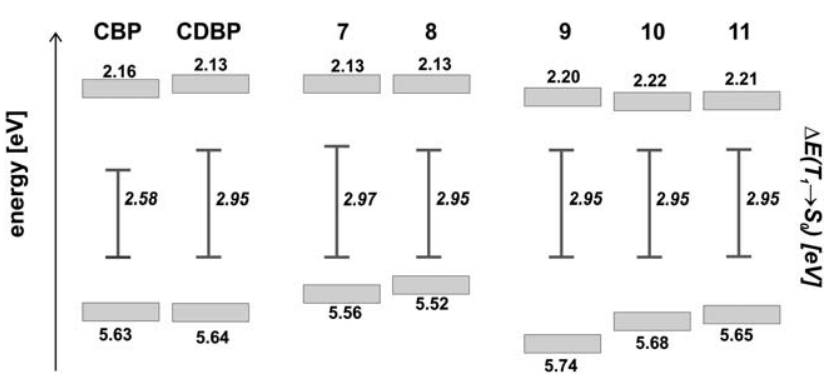

Fig. 4 Energy diagram showing the location of the HOMO and LUMO levels of the different CBP-derivatives. The solid line displays the position of the triplet energies $\Delta E\left(T_{1}-S_{0}\right)$.

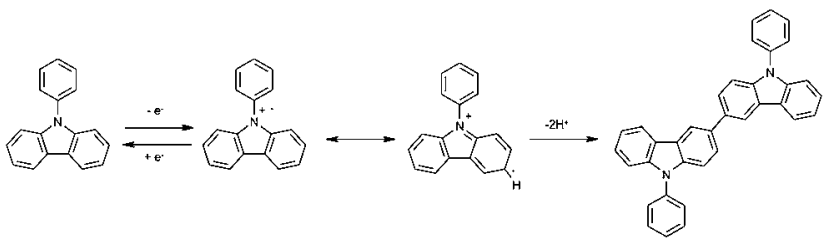

Fig. 6 Formation of the radical cation of $N$-phenylcarbazole upon oxidation and subsequent dimerisation at the active 3-position.

oligomeric species. The electrochemical behaviour of 7 is very similar to CBP. However, the signal between 0.4 and $0.6 \mathrm{~V}$ indicating the coupling of two carbazole units is growing more slowly compared with $\mathbf{C B P}$, as in compound $\mathbf{7}$ oligomerisation can occur only at the unblocked 6-position. In contrast, compound 8 reveals a fully reversible oxidation behavior which can be attributed to the complete blocking of the active 3- and 6position of the carbazole units.

\section{Experimental section}

\section{Materials}

All chemicals and reagents were used as received from commercial sources without further purification. 2,2'-Bis(trifluoromethyl)benzidine was synthesised according to a procedure described by Rogers et al. ${ }^{25}$ The solvents for reactions and purification were all distilled before use.

\section{Characterization}

${ }^{1} \mathrm{H}$ - and ${ }^{13} \mathrm{C}-\mathrm{NMR}$ spectra were recorded with a Bruker AC 300 (300 MHz, $75 \mathrm{MHz}$ ) and $\mathrm{CDCl}_{3}$ as a solvent. All data are given as chemical shifts $\delta$ (ppm) downfield from $\mathrm{Si}\left(\mathrm{CH}_{3}\right)_{4}$. For optical measurements, $10^{-5} \mathrm{M}$ cyclohexane solutions of the materials as well as thin films on quartz substrates were prepared. Both neat films and films with $10 \mathrm{wt} \%$ of the compound in poly(methylmethacrylate) were prepared by spincoating. The UV/Vis spectra were measured in solution and on neat films with a Hitachi U-3000 spectrometer. Fluorescence spectra in solution were obtained from a Shimadzu spectrofluorophotometer RF$5301 \mathrm{PC}$ using excitation at $300 \mathrm{~nm}$. The phosphorescence spectra were taken with the thin film samples mounted in a continuous flow helium cryostat. The temperature was controlled with an Oxford Intelligent temperature controller-4 (ITC-502). Excitation was provided by a pulsed, frequency-tripled $\mathrm{Nd}$ :YAG laser

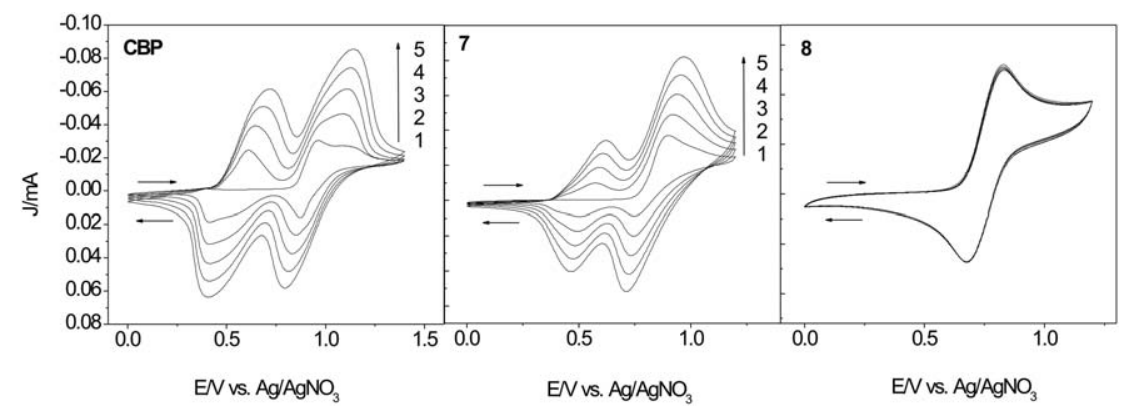

Fig. 5 Cyclic voltammograms of CBP, 7, and 8 (five scans, scan rate $50 \mathrm{mV} \mathrm{s}^{-1}, 2 \times 10^{-3} \mathrm{M}^{\text {in }} \mathrm{CH}_{2} \mathrm{Cl}_{2}$ ). 
at $355 \mathrm{~nm}(3.49 \mathrm{eV})$ (Spectron SL401). This wavelength corresponds to the red tail of the first absorption band in our compounds. The duration of the laser pulses was $6 \mathrm{~ns}$ and the laser was operated at a repetition rate of $10 \mathrm{~Hz}$ by a self-made electronic delay generator. The light emitted by the sample was dispersed and subsequently detected by a time gated intensified CCD camera (Andor iStar DH734-18F-9AM). The measurements were taken with a delay time of $500 \mathrm{~ns}$ and a gate width of $60 \mathrm{~ms}$. The measurements were carried out at an excitation density of about $250 \mu \mathrm{J} \mathrm{cm}^{-2}$ pulse $^{-1}$ on films of about $150 \mathrm{~nm}$ thickness as determined by a Dektak profilometer. To increase the signal-to-noise-ratio, all spectra were obtained by averaging over 2000 laser shots. For differential scanning calorimetry (DSC) measurements a Diamond DSC apparatus from Perkin Elmer was used (heating/cooling rate $10 \mathrm{~K} \mathrm{~min}^{-1}$ ). Thermogravimetric analysis (TGA) was performed on a Mettler Toledo TGA/SDTA815e machine at a heating rate of $10 \mathrm{~K} \mathrm{~min}^{-1}$ in a nitrogen atmosphere. Cyclic voltammetry measurements were carried out in absolute solvents measuring at a platinum working electrode versus a $\mathrm{Ag} / \mathrm{AgNO}_{3}$ reference electrode. Each measurement was calibrated against an internal standard (ferrocene/ferrocenium redox system). The purity of the target compounds was checked with a Waters size exclusion chromatography system (SEC) for oligomers (analytical columns: crosslinked polystyrene gel (Polymer Laboratories), length: $2 \times$ $60 \mathrm{~cm}$, width: $0.8 \mathrm{~cm}$, particle size: $5 \mu \mathrm{m}$, pore size: $100 \AA$, eluent: THF $\left(0.5 \mathrm{~mL} \mathrm{~min}^{-1}, 80 \mathrm{bar}\right)$, polystyrene standard $)$.

\section{Calculations}

Geometries were optimized using the BP86-functional ${ }^{26,27}$ in combination with a split-valence basis set $(\mathrm{SV}(\mathrm{P}))$ including polarization functions on all heavy atoms. ${ }^{28}$ All calculations were carried out with the turbomole program package. ${ }^{29}$

\section{Synthetic procedures}

\section{General procedure for the preparation of methyl substituted carbazoles \\ 3-Methyl-6,7,8,9-tetrahydro-5H-carbazole (1). 3-Methyl-} phenylhydrazine hydrochloride $(10.0 \mathrm{~g}, 63 \mathrm{mmol})$ was added to a solution of cyclohexanone $(6.2 \mathrm{~g}, 63 \mathrm{mmol})$ in acetic acid $(30 \mathrm{~mL})$ under an argon atmosphere over a period of one hour. After stirring at $80^{\circ} \mathrm{C}$ for half an hour the reaction mixture was extracted with dichloromethane and washed several times with $5 \%$ aqueous sodium hydrogen carbonate solution to neutralise the acetic acid. After drying the organic layer over anhydrous sodium sulfate the solvent was evaporated. Yield: $9.25 \mathrm{~g}(79 \%)$. EI-MS $m / z: 185\left(95, \mathbf{M}^{+}\right)$.

3,6-Dimethyl-6,7,8,9-tetrahydro-5H-carbazole (2). Compound $\mathbf{2}$ was prepared according to the procedure described for $\mathbf{1}$. Yield: $93 \%$.

3-Methylcarbazole (3). To $9.25 \mathrm{~g}(50 \mathrm{mmol})$ of 3-methyl6,7,8,9-tetrahydro-5 $\mathrm{H}$-carbazole (1) in $30 \mathrm{~mL}$ of $1,2,4$-trimethylbenzene was added $10 \%$ palladium on activated charcoal $(2.66 \mathrm{~g}, 25 \mathrm{mmol})$. The mixture was refluxed for $6 \mathrm{~h}$. In order to remove the catalyst the mixture was diluted with dichloromethane and filtered over neutral aluminium oxide. After the removal of dichloromethane, hexane was added and the product was obtained as white precipitate. Yield: $88 \%$. EI-MS $\mathrm{m} /$ $z: 181\left(100, \mathrm{M}^{+}\right) .{ }^{1} \mathrm{H}-\mathrm{NMR}\left(300 \mathrm{MHz}, \mathrm{CDCl}_{3}\right), \delta(\mathrm{ppm}): 8.06$ (dd, $1 \mathrm{H}), 7.94(\mathrm{~s}, 1 \mathrm{H}, \mathrm{NH}), 7.90(\mathrm{ds}, 1 \mathrm{H}), 7.41(\mathrm{~m}, 2 \mathrm{H}), 7.35(\mathrm{~d}, 1 \mathrm{H})$, 7.27-7.21 (m, 2H), 2.55 (s, 3H). ${ }^{13} \mathrm{C}-\mathrm{NMR}\left(75 \mathrm{MHz}, \mathrm{CDCl}_{3}\right)$, $\delta(\mathrm{ppm}): 139.82,137.71,137.26,128.75,127.18,125.65,123.14$, 120.26, 120.24, 119.22, 110.55, 110.24, 21.44.

3,6-Dimethylcarbazole (4). Compound 4 was prepared according to the procedure given for 3. Yield: $86 \%$. EI-MS $\mathrm{m} / \mathrm{z}$ : $195\left(100, \mathrm{M}^{+}\right)$. ${ }^{1} \mathrm{H}-\mathrm{NMR}\left(300 \mathrm{MHz}, \mathrm{CDCl}_{3}\right), \delta(\mathrm{ppm}): 7.85$ (m, $2 \mathrm{H}), 7.84(\mathrm{~s}, 1 \mathrm{H}, \mathrm{NH}), 7.31$ (d, 2H), $7.24(\mathrm{dd}, 2 \mathrm{H}), 2.55(\mathrm{~s}, 6 \mathrm{H})$. ${ }^{13} \mathrm{C}-\mathrm{NMR}\left(75 \mathrm{MHz}, \mathrm{CDCl}_{3}\right), \delta$ (ppm): 138.07, 128.48, 126.99, $123.41,120.18,110.22,21.44$.

\section{General procedure for the preparation of substituted biphenyls}

4,4'-Diiodo-2,2'-dimethylbiphenyl (5). 2,2'-Dimethylbenzidine dihydrochloride $(14.3 \mathrm{~g}, 50 \mathrm{mmol})$ was suspended in $125 \mathrm{~mL}$ of water and $15 \mathrm{~mL}$ of conc. hydrochloric acid and the suspension was cooled to $0-5{ }^{\circ} \mathrm{C}$. A solution of sodium nitrite $(7.18 \mathrm{~g}$, $100 \mathrm{mmol}$ ) in $20 \mathrm{~mL}$ of water was added dropwise. The resulting cold tetrazonium salt solution was added slowly to a well-stirred solution of iodine $(30.5 \mathrm{~g}, 120 \mathrm{mmol})$ and sodium iodide $(30.0 \mathrm{~g}$, $200 \mathrm{mmol}$ ) in $50 \mathrm{~mL}$ of water and $100 \mathrm{~mL}$ of dichloromethane at a temperature below $5{ }^{\circ} \mathrm{C}$. The mixture was stirred for $24 \mathrm{~h}$ at room temperature and the excess of iodine was removed by the addition of a sodium thiosulfate solution. The product was extracted with dichloromethane and washed several times with water. After drying the organic layer over anhydrous sodium sulfate, the solvent was evaporated and the residue was purified by column chromatography on silica gel with hexane as eluent to afford compound 5. Yield: $16.6 \mathrm{~g}(76 \%)$. EI-MS $\mathrm{m} / z$ : 434 (100, $\mathrm{M}^{+}$). ${ }^{1} \mathrm{H}-\mathrm{NMR}\left(300 \mathrm{MHz}, \mathrm{CDCl}_{3}\right), \delta(\mathrm{ppm}): 7.63(\mathrm{~d}, 2 \mathrm{H}), 7.55$ $(\mathrm{dd}, 2 \mathrm{H}), 6.79(\mathrm{~d}, 2 \mathrm{H}), 1.98(\mathrm{~s}, 6 \mathrm{H}) .{ }^{13} \mathrm{C}-\mathrm{NMR}\left(75 \mathrm{MHz}, \mathrm{CDCl}_{3}\right)$, $\delta$ (ppm): 139.99, 138.75, 138.22, 134.81, 130.87, 93.13, 19.47 .

4,4'-Diiodo-2,2'-bis(trifluoromethyl)biphenyl (6). Compound 6 was prepared according to the procedure given for 5 . Yield: $1.91 \mathrm{~g}(75 \%)$. EI-MS m/z: $542\left(100, \mathrm{M}^{+}\right) .{ }^{1} \mathrm{H}-\mathrm{NMR}(300 \mathrm{MHz}$, $\left.\mathrm{CDCl}_{3}\right), \delta(\mathrm{ppm}): 8.07(\mathrm{~d}, 2 \mathrm{H}), 7.89(\mathrm{dd}, 2 \mathrm{H}), 6.99(\mathrm{~d}, 2 \mathrm{H}) .{ }^{13} \mathrm{C}-$ $\operatorname{NMR}\left(75 \mathrm{MHz}, \mathrm{CDCl}_{3}\right), \delta(\mathrm{ppm}): 139.97,135.88,135.06,132.86$, $130.32\left(\mathrm{q},{ }^{2} J(\mathrm{C}-\mathrm{F})=30.8 \mathrm{~Hz}\right), 122.56\left(\mathrm{q},{ }^{1} J(\mathrm{C}-\mathrm{F})=273.0 \mathrm{~Hz}\right)$, 93.55 .

\section{General procedure for the Ullmann condensation}

4,4'-Bis(3-methylcarbazolyl)-2,2'-dimethylbiphenyl (7). 4,4'Diiodo-2,2'-dimethylbiphenyl (5) (1 g, $2.3 \mathrm{mmol})$, 3-methylcarbazole (3) $(1.0 \mathrm{~g}, 5.52 \mathrm{mmol})$, potassium carbonate $(2.5 \mathrm{~g}, 18.4$ $\mathrm{mmol})$, copper powder $(0.58 \mathrm{~g}, 9.2 \mathrm{mmol})$ and 18-crown-6 $(0.12 \mathrm{mg}, 0.46 \mathrm{mmol})$ were refluxed in $15 \mathrm{~mL}$ of $o$-dichlorobenzene in an argon atmosphere for $24 \mathrm{~h}$. Copper and inorganic salts were filtered off and the solvent was evaporated. Column chromatography on silica gel with hexane/tetrahydrofuran $(20: 1)$ as eluent yielded $0.72 \mathrm{~g}(58 \%)$ of 7 as white solid. EI-MS $m / z$ : 540 $\left(100, \mathrm{M}^{+}\right) .{ }^{1} \mathrm{H}-\mathrm{NMR}\left(300 \mathrm{MHz}, \mathrm{CDCl}_{3}\right), \delta(\mathrm{ppm}): 8.14(\mathrm{~d}, 4 \mathrm{H})$, $7.97(\mathrm{~m}, 4 \mathrm{H}), 7.55-7.43(\mathrm{~m}, 12 \mathrm{H}), 7.32-7.27(\mathrm{~m}, 4 \mathrm{H}), 2.58(\mathrm{~s}, 6 \mathrm{H})$, 2.29 (s, $6 \mathrm{H}) .{ }^{13} \mathrm{C}-\mathrm{NMR}\left(75 \mathrm{MHz}, \mathrm{CDCl}_{3}\right), \delta(\mathrm{ppm}): 141.11$, $139.83,139.23,137.88,137.11,130.78,129.31,128.19,127.24$, 
$125.76,124.16,123.57,123.30,120.28,119.72,109.88,109.65$, 21.45, 20.17. $T_{\mathrm{m}}:-{ }^{\circ} \mathrm{C} ; T_{\mathrm{g}}: 106^{\circ} \mathrm{C}$.

4,4'-Bis(9-carbazolyl)-2,2'-dimethylbiphenyl (CDBP), 4,4'-bis(3,6-dimethylcarbazolyl)-2,2'-dimethylbiphenyl (8), 4,4'bis(9-carbazolyl)-2,2'-bis(trifluoromethyl)biphenyl (9), ${ }^{30} 4,4^{\prime}$ bis(3-methylcarbazolyl)-2,2'-bis(trifluoromethyl)biphenyl (10), and 4,4'-bis(3,6-dimethylcarbazolyl)-2,2'-bis(trifluoromethyl)biphenyl (11) were prepared according to the procedure given for 7 .

4,4'-Bis(9-carbazolyl)-2,2'-dimethylbiphenyl (CDBP). Yield: $0.59 \mathrm{~g}(50 \%)$. EI-MS m/z: $512\left(100, \mathrm{M}^{+}\right) .{ }^{1} \mathrm{H}-\mathrm{NMR}(300 \mathrm{MHz}$, $\left.\mathrm{CDCl}_{3}\right), \delta(\mathrm{ppm}): 8.20(\mathrm{~d}, 4 \mathrm{H}), 7.58-7.45(\mathrm{~m}, 14 \mathrm{H}), 7.36-7.31(\mathrm{~m}$, $4 \mathrm{H}), 2.31(\mathrm{~s}, 6 \mathrm{H}) .{ }^{13} \mathrm{C}-\mathrm{NMR}\left(75 \mathrm{MHz}, \mathrm{CDCl}_{3}\right), \delta(\mathrm{ppm}): 140.96$, $140.01,137.95,136.92,130.81,128.36,125.94,124.34,123.42$, 120.36, 119.94, 109.94, 20.17. $T_{\mathrm{m}}:-{ }^{\circ} \mathrm{C} ; T_{\mathrm{g}}: 94{ }^{\circ} \mathrm{C}$.

4,4'-Bis(3,6-dimethylcarbazolyl)-2,2'-dimethylbiphenyl (8). Yield: $0.7 \mathrm{~g}(50 \%)$. EI-MS $\mathrm{m} / \mathrm{z}$ : $568\left(100, \mathrm{M}^{+}\right) .{ }^{1} \mathrm{H}-\mathrm{NMR}(300$ $\left.\mathrm{MHz} \mathrm{CDCl}_{3}\right), \delta$ (ppm): 7.93 (ds, 4H), 7.52-7.40 (m, 10H), 7.26 $(\mathrm{dd}, 4 \mathrm{H}), 2.57$ (s, 12H), $2.28(\mathrm{~s}, 6 \mathrm{H}) .{ }^{13} \mathrm{C}-\mathrm{NMR}\left(75 \mathrm{MHz}, \mathrm{CDCl}_{3}\right.$ ), $\delta$ (ppm): 139.64, 139.40, 137.82, 137.32, 130.75, 129.06, 128.01, $127.07,123.98,123.46,120.22,109.60,21.45,20.19 . T_{\mathrm{m}}: 277^{\circ} \mathrm{C}$; $T_{\mathrm{g}}: 121^{\circ} \mathrm{C}$.

4,4'-Bis(9-carbazolyl)-2,2'-bis(trifluoromethyl)biphenyl (9). Yield: $0.71 \mathrm{~g}(62 \%)$. EI-MS m/z: $620\left(100, \mathrm{M}^{+}\right)$. ${ }^{1} \mathrm{H}-\mathrm{NMR}(300$ $\left.\mathrm{MHz}, \mathrm{CDCl}_{3}\right), \delta(\mathrm{ppm}): 8.20(\mathrm{~d}, 4 \mathrm{H}), 8.09(\mathrm{~d}, 2 \mathrm{H}), 7.93(\mathrm{dd}, 2 \mathrm{H})$, $7.71(\mathrm{~d}, 2 \mathrm{H}), 7.55-7.48(\mathrm{~m}, 8 \mathrm{H}), 7.40-7.35(\mathrm{~m}, 4 \mathrm{H}) .{ }^{13} \mathrm{C}-\mathrm{NMR}(75$ $\mathrm{MHz}, \mathrm{CDCl}_{3}$ ), $\delta$ (ppm): 140.41, 138.33, 135.32, 133.49, 133.41, $130.90\left(\mathrm{q},{ }^{2} J(\mathrm{C}-\mathrm{F})=31.5 \mathrm{~Hz}\right), 129.15,126.48,124.68,123.83$, $123.44\left(\mathrm{q},{ }^{1} J(\mathrm{C}-\mathrm{F})=272.3 \mathrm{~Hz}\right), 120.76,120.60,109.50 . T_{\mathrm{m}}:$ $232{ }^{\circ} \mathrm{C} ; T_{\mathrm{g}}: 100{ }^{\circ} \mathrm{C}$.

4,4'-Bis(3-methylcarbazolyl)-2,2'-bis(trifluoromethyl)biphenyl (10). Yield: $0.8 \mathrm{~g}(55 \%)$. EI-MS $m / z$ : $648\left(100, \mathrm{M}^{+}\right) .{ }^{1} \mathrm{H}-\mathrm{NMR}$ $\left(300 \mathrm{MHz}, \mathrm{CDCl}_{3}\right) \delta(\mathrm{ppm}): 8.15(\mathrm{~d}, 2 \mathrm{H}), 8.07(\mathrm{~d}, 2 \mathrm{H}), 7.99(\mathrm{~m}$, $2 \mathrm{H}), 7.86(\mathrm{dd}, 2 \mathrm{H}), 7.68(\mathrm{~d}, 2 \mathrm{H}), 7.54-7.30(\mathrm{~m}, 10 \mathrm{H}), 2.60(\mathrm{~s}, 6 \mathrm{H})$. ${ }^{13} \mathrm{C}-\mathrm{NMR}\left(75 \mathrm{MHz}, \mathrm{CDCl}_{3}\right), \delta(\mathrm{ppm}): 140.56,138.66,138.51$, $135.10,133.37,130.82\left(\mathrm{q},{ }^{2} J(\mathrm{C}-\mathrm{F})=30.8 \mathrm{~Hz}\right), 130.22,128.90$, $127.63,126.20,124.48,123.99,123.74,123.46\left(\mathrm{q},{ }^{1} J(\mathrm{C}-\mathrm{F})=273.8\right.$ $\mathrm{Hz}), 120.56,120.50,109.45,109.22,21.43 . T_{\mathrm{m}}: 210{ }^{\circ} \mathrm{C} ; T_{\mathrm{g}}$ : $105^{\circ} \mathrm{C}$.

4,4'-Bis(3,6-dimethylcarbazolyl)-2,2'-bis(trifluoromethyl)biphenyl (11). Yield: $1.4 \mathrm{~g}(56 \%)$. EI-MS $m / z$ : $676\left(100, \mathrm{M}^{+}\right) .{ }^{1} \mathrm{H}-\mathrm{NMR}$ (300 MHz, $\mathrm{CDCl}_{3}$ ), $\delta$ (ppm): 8.05 (d, 2H), 7.95 (m, 4H), 7.85 (dd, $2 \mathrm{H}), 7.66(\mathrm{~d}, 2 \mathrm{H}), 7.42(\mathrm{~d}, 4 \mathrm{H}), 7.30(\mathrm{dd}, 4 \mathrm{H}), 2.59$ (s, $12 \mathrm{H}) .{ }^{13} \mathrm{C}-$ NMR (75 MHz, $\mathrm{CDCl}_{3}$ ), $\delta$ (ppm): 138.82, 138.71, 134.87, 133.34, $130.75\left(\mathrm{q},{ }^{2} J(\mathrm{C}-\mathrm{F})=30.8 \mathrm{~Hz}\right), 130.00,128.66,127.46,124.25,123.91$, $123.50\left(\mathrm{q},{ }^{1} J(\mathrm{C}-\mathrm{F})=272.3 \mathrm{~Hz}\right), 120.46,109.18,21.43 . T_{\mathrm{m}}: 233{ }^{\circ} \mathrm{C}$; $T_{\mathrm{g}}: 119^{\circ} \mathrm{C}$.

\section{Conclusions}

We have described a number of CBP derivatives in which the substitution in the 2- and 2 -position of the biphenyl and in the 3and 6-position of the carbazole unit is systematically varied. This substitution of the parent crystalline CBP leads to the materials
7-11 which have a much lower tendency to crystallise. Their glass transition temperatures range from $94-121^{\circ} \mathrm{C}$. The highest glass transition temperatures were determined for 3,6-dimethylcarbazole bearing derivatives 8 and $\mathbf{1 1}$ with $121{ }^{\circ} \mathrm{C}$ and $119^{\circ} \mathrm{C}$, respectively.

The main effect of the methyl substitution in 2- and 2'-position of the biphenyl unit is a twisting of the two central phenyl rings. Due to this electronic decoupling, the conjugation length in the molecule is limited which causes an increase of the triplet energy $\Delta E\left(T_{1}-S_{0}\right)$ from $2.58 \mathrm{eV}$ for CBP to $2.95-2.97 \mathrm{eV}$ for 7-11.

Fine-tuning of the energy levels, especially the HOMO levels, can be achieved by a suitable choice of substitution pattern of the CBP derivatives. Cyclic voltammetry with repeated cycles shows that by introducing substituents at the 3- and 6-position of the pendant carbazole units the oxidation to the radical cation becomes fully reversible and thus electrochemical stable host materials are accessible.

\section{Acknowledgements}

The authors thank Irene Bauer and Dr Michael Rothmann for the help during synthesis and characterisation of the novel CBP derivatives. We also thank Dr Ingo Münster, Dr Evelyn Fuchs and Dr Nicolle Langer for fruitful discussions. Financial support from the BMBF project TOPAS 2012 (FKZ 13N 10447) is gratefully acknowledged. P.S. thanks the Universität Bayern e.V. for a grant.

\section{References}

1 M. A. Baldo, D. F. O’Brian, Y. You, A. Shoustikov, S. Sibley, M. E. Thompson and S. R. Forrest, Nature (London, U. K.), 1998, 395, $151-154$.

2 D. F. O'Brian, M. A. Baldo, M. E. Thompson and S. R. Forrest, Appl. Phys. Lett., 1999, 74(4), 442-444.

3 M. A. Baldo, S. Lamansky, P. E. Burrows, M. E. Thompson and S. R. Forrest, Appl. Phys. Lett., 1999, 75, 4-6.

4 S. Tokito, T. Iijima, T. Tsuzuki and F. Sato, Appl. Phys. Lett., 2003, 83, 2459-2461.

5 C. Adachi, M. A. Baldo, M. E. Thompson and S. R. Forrest, J. Appl. Phys., 2001, 90, 5048-5051.

6 S. Lamansky, P. Djurovich, D. Murphy, F. A. Razzaq, C. Adachi, P. E. Burrows, S. R. Forrest and M. E. Thompson, J. Am. Chem. Soc., 2001, 123, 4304-4312.

7 V. Adamovich, J. Brooks, A. Tamayo, A. M. Alexander, P. Djurovich, B. W. D'Andrade, C. Adachi, S. R. Forrest and M. E. Thompson, New J. Chem., 2002, 26, 1171-1178.

8 R. J. Holmes, S. R. Forrest, Y. J. Tung, R. C. Kwong, J. J. Brown, S. Garon and M. E. Thompson, Appl. Phys. Lett., 2003, 82, 24222424.

9 S. Tokito, T. Iijima, Y. Suzuri, H. Kita, T. Tsuzuki and F. Sato, Appl. Phys. Lett., 2003, 83, 569-571.

10 I. Tanaka, Y. Tabata and S. Tokito, Chem. Phys. Lett., 2004, 400, 8689.

11 G. Lei, L. Wang and Y. Qiu, Appl. Phys. Lett., 2004, 85, 5403-5405.

12 E. L. Williams, K. Haavisto, J. Li and G. E. Jabbour, Adv. Mater., 2007, 19, 197-202.

13 S.-J. Su, H. Sasabe, T. Takeda and J. Kido, Chem. Mater., 2008, 20, 1691-1693.

14 J. He, H. Lui, X. Dai, X. Ou, J. Wang, S. Tao, X. Zhang, P. Wang and D. Ma, J. Phys. Chem. C, 2009, 113, 6761-6767.

15 P. Strohriegl and J. V. Grazulevicius, Adv. Mater., 2002, 14, 1439 1452.

16 Y. Shirota, J. Mater. Chem., 2000, 10, 1-25.

17 R. Schmechel and H. Von Seggern, Phys. Status Solidi A, 2004, 201, $1215-1235$. 
18 M.-H. Tsai, H.-W. Lin, H.-C. Su, T.-H. Ke, C.-C. Wu, F.-C. Fang, Y.-L. Liao, K.-T. Wong and C.-I. Wu, Adv. Mater., 2006, 18, 12161220.

19 M.-H. Tsai, T.-H. Ke, H.-W. Lin, C.-C. Wu, S.-F. Chiu, F.-C. Fang, Y.-L. Liao, K.-T. Wong, Y.-H. Chen and C.-I. Wu, ACS Appl. Mater. Interfaces, 2009, 1, 567-574.

20 M. Kuroki and Y. Tsunashima, J. Heterocycl. Chem., 1981, 18, 709714.

21 E. C. Horning, M. G. Horning and G. N. Walker, J. Am. Chem. Soc., 1948, 70, 3935-3936.

22 H.-W. Schmidt and D. Guo, Makromol. Chem., 1988, 189, 20292037.

23 J. F. Ambrose and R. F. Nelson, J. Electrochem. Soc., 1968, 115(11), 1159-1164.
24 J. F. Ambrose, L. L. Carpenter and R. F. Nelson, J. Electrochem. Soc., 1975, 122(7), 876-894.

25 H. G. Rogers, R. A. Gaudiana, W. C. Hollinsed, P. S. Kalyanaraman, J. S. Manello, C. McGowan, R. A. Minns and R. Sahatjian, Macromolecules, 1985, 18, 1058-1068.

26 J. P. Perdew and W. Yue, Phys. Rev. B: Condens. Matter Mater. Phys., 1986, 33, 8800-8802.

27 A. D. Becke, Phys. Rev. A: At., Mol., Opt. Phys., 1988, 36, 3098-3100.

28 A. Schäfer, H. Horn and R. Ahlrichs, J. Chem. Phys., 1992, 97, 25712577.

29 R. Ahlrichs, M. Bär, M. Häser, H. Horn and C. Kölmel, Chem. Phys. Lett., 1989, 162, 165-169.

30 Z. Ge, T. Hayakawa, S. Ando, M. Ueda, T. Akiike, H. Miyamoto, T. Kajita and M. Kakimoto, Chem. Lett., 2008, 37(3), 294-295. 